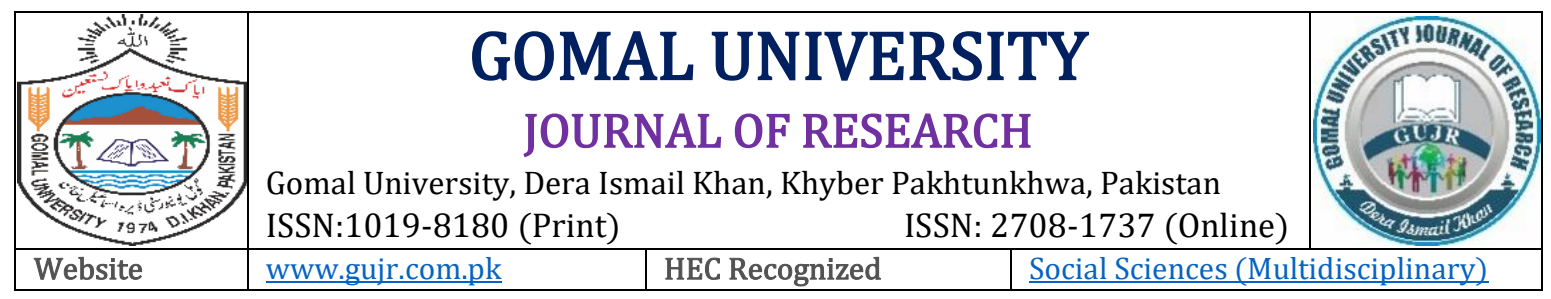

\title{
IS CLIMATE INDICATOR AFFECTS TRANSMISSION OF COVID-19 PANDEMIC: CLIMATIC IMPACTS ON COVID-19 TRANSMISSION
}

Muhammad Asif Khan', Muhammad Waseem Khan'2 \& Asima Siddique ${ }^{3}$
'School of Management, Huazhong University of science and technology Wuhan, Hubei, CHINA
2Tongji Medical College, Huazhong University of science and technology Wuhan, Hubei, CHINA
3Department of Management Science, Comsats University, Islamabad, Pakistan

\section{INTRODUCTION}

In December 2019, world health organization received reports from Wuhan, Hubei China (Chen, Liang, Yuan, Hu, Xu, Zhao \& Zhu, 2020) stated that there are pneumonia cases for the first time. Still, the etiology is unknown (Atri, Siddiqi, Lang, Nauffal, Morrow \& Bohula, 2020). In January, the Chinese government said that it's a new type of coronavirus COVID-19. It affects all groups of people but people with old age and having preexisting diseases are more vulnerable to this COVID19. It affects the respiratory system of the individual that causes death. The primary symptoms of this disease are fever, cough, and shortness of breath. Due to the high rate of human-to-human transmission, the WHO declared as the infectious disease results in public health emergency and officially called COVID-19. Human to human and respiratory droplets are the primary reason for transmission of COVID-19. The incubation period of COVID-19 is from 2-14 days (WHO, 2020). In severe cases of COVID-19 effects respiratory system, kidney failure, and deaths. The symptoms of COVID-19 are similar to symptoms of SARS and MERS. As per Nature, transmission of COVID- 
19 is becoming unstoppable and already reached to point that WHO declared COVID-19 as global pandemic on $11^{\text {th }}$ March 2020. Till now due to COVID-19 confirmed cases are 2903098 and deaths are 202818.

The spread of COVID-19 is expected to be more in a cold and humid climate as compared to warm and dry environment, similar to behaviors of seasonal flu-like virus (Tamerius, Shaman, Alonso, Bloom, Uejio, Comrie \& Viboud, 2013). The other type of coronaviruses, such as SARS and MERS, also spread in cold and humid weather (Casanova, Jeon, Rutala, Weber, \& Sobsey, 2010). Human to human contact and respiratory droplets are main source of transmission of COVID-19. (Casanova et al., 2010) Stated that various environmental factors such as temperature and humidity might affect the spreading of COVID-19 by effecting its survival in the transmission routes. In Pakistan, the first case of the COVID-19 was reported in Karachi on 26th Feb2020, and it's quickly spread throughout the country, and every part of country have reported COVID-19 cases. On April 24, 2020, total number of confirmed cases are more than 11 thousand. The cases reported by different provinces are Sindh (3671), Punjab (4767), Khyber Pakhtunkhwa (1541), Baluchistan (607), and GB/AJK (355) and Islamabad (214) have confirmed cases. While so far, total number of deaths in Pakistan due to COVID-19 is 237. Fig-1 shows total number of confirmed cases in Pakistan, while Fig-2 show number of deaths in Pakistan due to COVID-19. Trend of graph show that upcoming weeks will be robust and number of cases and deaths are expected to be increased seeing given situation.

Figure 1

Number of Confirmed Cases (WHO, 202O)

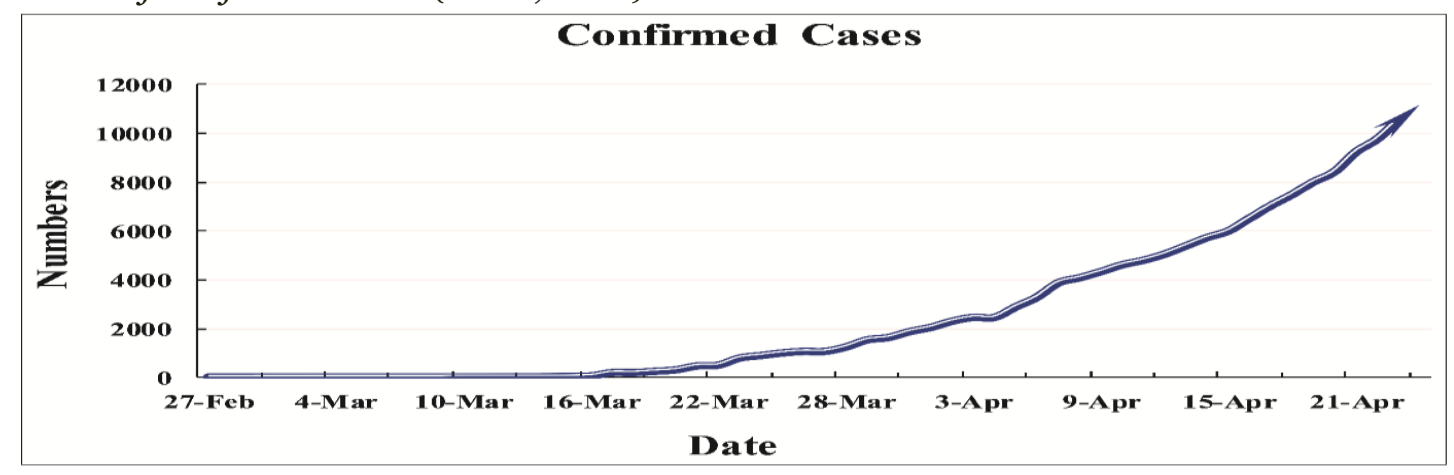

Figure 2

Number of Deaths Cases (WHO, 2O2O)

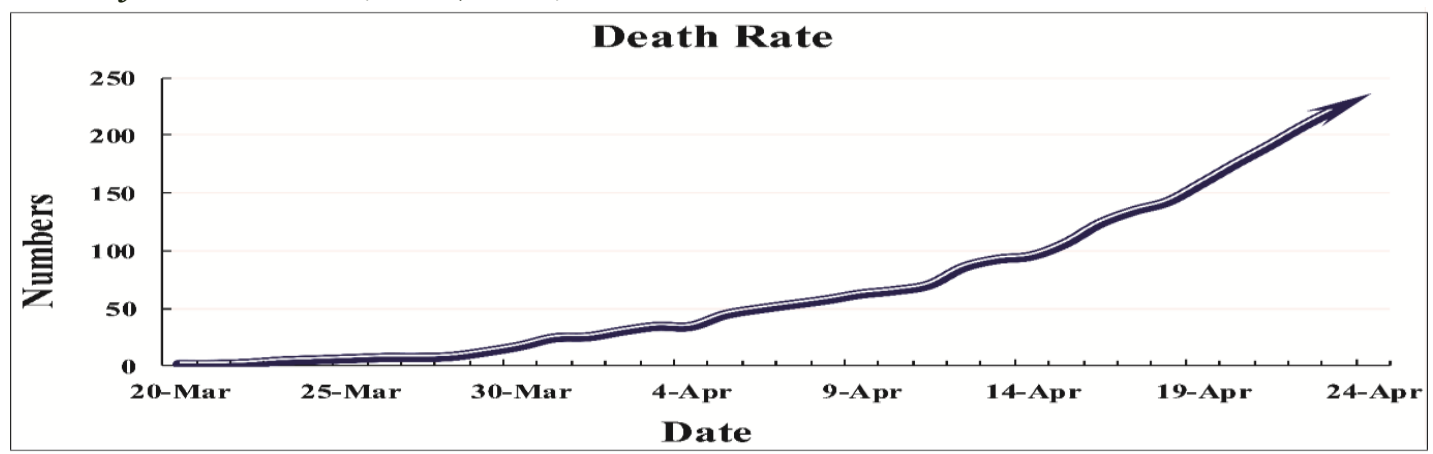


It is evident that there is a strong correlation amid virus transmission and weather conditions and studies confirmed that temperature, wind speed, and humidity are the primary source of the viral transmission (Yuan, Yun, Lan, Wang, Sullivan, Jia \& Bittles, 2006). The mortality rate of the virus rate is highly associated with weather variation (Bull, 1980). Epstein (2001) stated that weather conditions played a crucial role in the transmission of the West Nile virus in Europe and the USA. (Dalziel, Kissler, Gog, Viboud, Bjørnstad, Metcalf \& Grenfell, 2018) indicated that the population density and weather condition play crucial role in transfer of virus among human. Climate factors like daily weather and long term climate situation may affect transmission of infectious disease (Yuan et al., 2006). The humidity and daily temperature may affect the transmission of the virus by affecting the tenacity of its transmission in routes (Casanova et al., 2010). Bedford, Riley, Barr, Broor, Chadha, Cox and Kelso (2015) stated that climate and weather conditions factors affects the transmission of the virus along with incubation period. Bull (1980) stated that the mortality rate of virus is positively associated changes in climate condition and different climate condition effect the virus transmission differently. Ficetola and Rubolini (2020); Iqbal, Fareed, Shahzad, He, Shahzad and Lina (2020); Tosepu, Gunawan, Effendy, Lestari, Bahar and Asfian (2020) state that there is positive correlation between COVID-19 and climate condition while some researcher found there is no correlation between climate and COVID-19 transmission (Jamil, Alam, Gojobori, \& Duarte, 2020; Shi, Dong, Yan, Zhao, Li, Liu, Xi (2020). Yuan et al. (2006) stated that with increase in temperature the transmission of virus decreases however not confirmed in many cases and this outcome has been supported by (Gupta, Bhatt, Roy, \& Chauhan, 2020) through their outcome.

\section{Research Problem}

Research on weather variation and COVID-19 is minimal around globe, particularly in Pakistan. This research will study the impact of climate variation on COVID-19 concerning Pakistan. The significance of this study will help the readers to understand the impact of weather factors on the transmission of COVID-19. To better understand outcome of this the following research questions are addressed in this study. The impact of temperature, Humidity and wind flow on COVID-19 in Pakistan.

\section{RESEARCH METHODOLOGY}

Karachi is the biggest city in Pakistan and located in the southeastern part of the country. Karachi is known as the financial hub of Pakistan and the population of the town is around 20 million and covers about $3527 \mathrm{~km}$ square area. The geographical coordinates of Karachi are $24^{\circ} 51^{\prime} 36^{\prime \prime} \mathrm{N}$ and $67^{\circ} 00^{\prime} 36^{\prime \prime} \mathrm{E}$. The city is located at coast of the Arabian Sea due to marine affects the climate of Karachi is moderate. Average rainfall in Karachi is around 7 inches per year. So, for data, data for COVID-19 is obtained from world health organization and ministry of health, Pakistan. In contrast, climate data about diverse indicators are collected from Pakistan meteorological department (see Table 1).

\section{Table 1}

Research Variables

\begin{tabular}{lll}
\hline Variables & Measurement & Source \\
\hline COVID-19 & Confirmed cases & WHO \\
Temperature & Max and Min & Pakistan Meteorological Department (PMD) \\
Humidity & Percentage & PMD \\
\hline Wind flow & Km/hr. & PMD \\
\hline
\end{tabular}




\section{RESULTS AND DISCUSSION}

The study was conducted to understand the impact of different climate variables on transmission of novel COVID-19 around the world concerning the Karachi, Pakistan. The data ranges from 25th Feb to 25th April 2020. The figure 3 shows maximum and minimum temperatures. Series one in Figure 3 shows the minimum temperature curve for the city understudy, while series 2 shows the maximum temperature in the city. In this connection, the outcome from results indicates that the lowest minimum temperature was 13.5 degrees, while the highest minimum temperature was 26.2 degrees. The results also show that the lowest maximum temperature was 25.3, as well as the highest maximum temperature was 41 degrees. It shows that the temperature of the Karachi is moderate.

\section{Figure 3}

Max and Min Temp

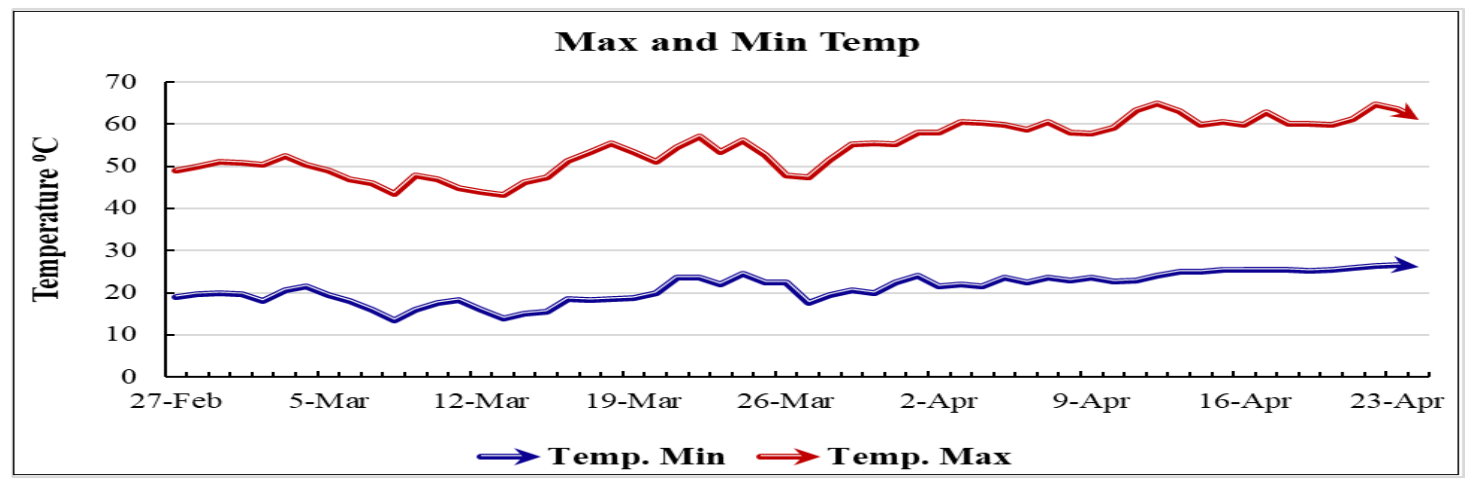

Figure 4 shows that the humidity percentage in the air. The findings show that the environment of the city is more humid, and the minimum humidity percentage in the air was 30 percent, and the highest was 84 percent. The outcome also shows that most of the time the environment is more humid.

\section{Figure 4}

Humidity in Air

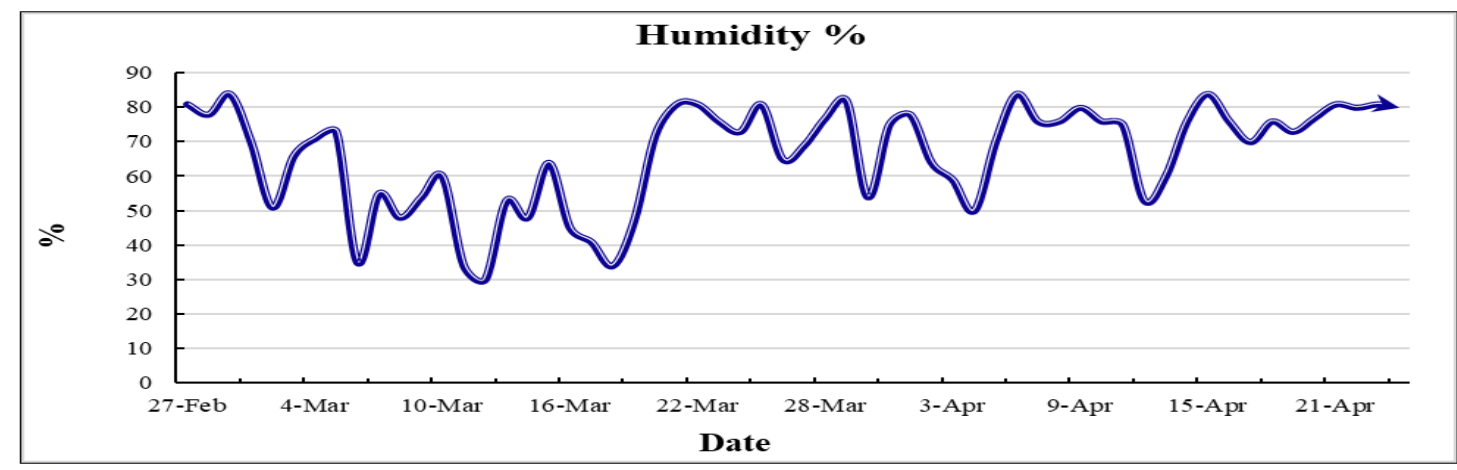

Figure 5 shows the speed of the wind in the concerned city for the period under study. The results that the maximum speed of the wind during this time was $30 \mathrm{~km} / \mathrm{hr}$ and the lowest was $10 \mathrm{~km} / \mathrm{hr}$. Consequently, we can say that the average speed of the wind is about 15 to $20 \mathrm{~km} / \mathrm{hr}$ during this period. 
Figure 5

Wind Flow

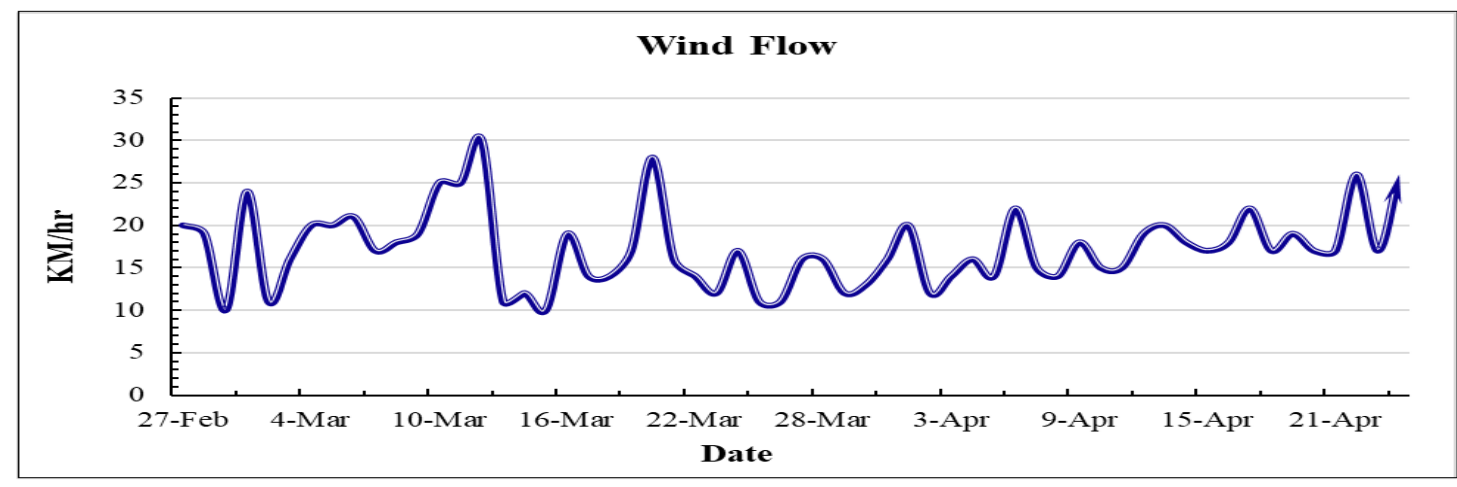

\section{Descriptive Statistics}

Table 2 shows the descriptive statistics of the research variable. Among the research variables, the mean value for confirmed patients as 2591.84, with a standard deviation of 3191.23. The mean value for humidity variable is 66.60 , with a standard deviation of 14.83 . While for wind flow, the results show $(\mathrm{SD}=4.56$ and $\mathrm{M}=17.27$ and mean value for temperature maximum is 33.36 and its standard deviation is 3.41 and standard deviation for temperature minimum is 3.45 , mean value is 21.25 .

Table 2

Descriptive Statistics

\begin{tabular}{lccccc}
\hline Variables & Min & Max & Mean & Standard deviation & Observation \\
\hline Patients & 2 & 11155 & 2591.84 & 3191.23 & 58 \\
Deaths & 2 & 237 & 72.80 & 70.26 & 36 \\
Temp. Max & 25.3 & 41 & 33.36 & 3.41 & 58 \\
Temp. Min & 13.5 & 26.5 & 21.25 & 3.45 & 58 \\
Humidity & 30 & 84 & 66.60 & 14.83 & 58 \\
\hline Wind flow & 10 & 30 & 17.27 & 4.56 & 58 \\
\hline
\end{tabular}

\section{Correlation Analysis}

Table 3 shows the correlation matrix between COVID-19 and climate indicators, and results show that all variables are positively and significantly correlated with the COVID-19. The correlation between COVID-19 and temperature maximum and the minimum is .79 and .60, which they have sixty and seventy-nine percent effect upon COVID-19 in case of Pakistan. the correlation provides the association as correlation between humidity and the dependent variable is 44 percent, while wind flow is 19 percent. The association between minimum temperature, humidity and wind flow is negative.

Table 3

Correlation Matrix

\begin{tabular}{lcccc}
\hline Variables & Patients & Temp max & Temp min & Humidity \\
\hline Patients & 1 & & & \\
Temp Max & 0.7952 & 1 & & \\
Temp Min & 0.6077 & 0.5616 & 1 & \\
Humidity & 0.4479 & 0.6436 & 0.1850 & 1 \\
\hline Wind Flow & 0.1930 & 0.0913 & -0.0949 & -0.096 \\
\hline
\end{tabular}




\section{Regression Analysis}

Table 4 shows the impact of climate indicators upon the novel COVID-19 concerning Pakistan's environment. Table 4 displays that all climate variables have a positive effect on COVID-19. The relationship between COVID-19 and temperature minimum is most robust among variables $(\beta=$ $568.28, \mathrm{P}=.000$ ) which shows that they have positive and significant association with each other. The impact of temperature maximum is also positive and significant. Coefficient of temperature is 256.64, and its significant value is 0.007 , so temp maximum has a positive impact upon COVID19 in the case of Karachi Pakistan. The table depicts that the association between COVID-19 and humidity is positive but not significant, while a strong association between wind flow and COVID19. $\mathrm{R}$ square value for model is 0.69 , which means that model has 69 percent have explanatory power.

Table 4

Regression Analysis

\begin{tabular}{lcccc}
\hline COVID-19 & Coefficient & Standard error & T & P \\
\hline Temp min & 568.2806 & 119.0288 & 4.77 & 0.000 \\
Temp max & 256.6459 & 91.92287 & 2.79 & 0.007 \\
Humidity & 3.757941 & 23.03081 & 0.16 & 0.871 \\
Wind flow & 115.0846 & 56.08478 & 2.05 & 0.045 \\
\hline Constant & -20286.6 & 2835.171 & -7.16 & 0.000 \\
\hline
\end{tabular}

R square $=0.6954$, adjusted $\mathrm{R}$ square $=0.6725$

\section{DISCUSSION}

This research investigated the different climate indicators on COVID-19 concerning the Pakistan environment. Our results show that the average maximum temperature of the study area is about 33.36. In contrast, the average minimum temperature is 21.25 degrees, and studies show that this COVID-19 can easily survive in this temperature. So, this kind of temperature is beneficial in virus transmission. Table 2 also indicates that humidity is even higher in the study area, so it can also increase spreading of COVID-19. Table 3 shows that all climate variables are positively correlated with COVID-19. Our findings show that temperature minimum and maximum are undoubtedly and significantly associated with transmission of COVID-19, which is similar to the previous study of (Vandini, Corvaglia, Alessandroni, Aquilano, Marsico, Spinelli \& Faldella, 2013). The results also show that humidity and wind flow have a positive correlation with novel- COVID-19, which confirms that both play roles in the spreading of the virus (Huang, Wang, Li, Ren, Zhao, Hu \& Gu, 2020). Table 4 shows that there is the positive association between COVID-19 and temperature minimum $(\mathrm{B}=568.38, \mathrm{P}=0.000)$ and temperature maximum $(\mathrm{B}=256.64, \mathrm{P}=0.007)$, which shows that temp plays a role in the spreading of the virus. Our result is supported by (Shi et al., 2020). The findings portray that there is a positive association between humidity and COVID-19, which is similar to the outcome of (Sajadi, Habibzadeh, Vintzileos, Miralles-wilhelm, \& Amoroso, 1992). Our findings also show that there is positive and significant between the research variables $(\mathrm{B}=$ 115.08, $\mathrm{P}=0.04$ ). This result is similar to the results (Tamerius, Shaman, Alonso, Bloom, Uejio, Comrie \& $\mathrm{Gu}, 2020$ ), which states that wind flow plays a role in the spreading of the virus. So, from the above findings, we confirmed that climate indicators such as temperature maximum, temperature minimum, wind flow, and humidity contribute to the spreading of virus among the individuals.

\section{CONCLUSION}

Climate indicators are vital in the war against COVID-19 in Pakistan. This study finds the impact of climate indicators on COVID-19 transmission. The outcome shows that temperature, humidity, 
and wind flow have a positive impact on COVID-19 transmission. The analysis further confirmed that temp min has a significant impact on COVID-19 transmission compared to the other climate indicators. The quality of air should be improved because it will decrease the transmission of viral diseases like COVID-19. The government should provide shelter and warm places to needy ones to keep them safe from COVID-19. To control and stop spreading virus, government of Pakistan should give more attention to make awareness to social distancing among their citizen, provide necessary facilities to peoples at their doors to avoid exposure to open environment. This research is limited to a specific geographic location; thus, it limits its implication. Also, few variables are taken in the research study, so one can assume other variables to study their association. Due to COVID-19 majority of production units have stopped their production. Hence, as a result, the air quality of the environment improved so one can conduct future research on COVID-19 impact on carbon emission. Cross country investigation in a different region will help to better cope with the COVID-19.

\section{REFERENCES}

Atri, D., Siddiqi, H. K., Lang, J., Nauffal, V., Morrow, D. A., \& Bohula, E. A. (2020). COVID-19 for the Cardiologist: A Current Review of the Virology, Clinical Epidemiology, Cardiac and Other Clinical Manifestations and Potential Therapeutic Strategies. JACC: Basic to Translational Science.

Bedford, T., Riley, S., Barr, I. G., Broor, S., Chadha, M., Cox, N. J., \& Kelso, A. (2015). Global circulation patterns of seasonal influenza viruses vary with antigenic drift. Nature, 523(7559), 217-220.

Bull, G. M. (1980). The weather and deaths from pneumonia. The Lancet, 315(8183), 1405-1408.

Casanova, L. M., Jeon, S., Rutala, W. A., Weber, D. J., \& Sobsey, M. D. (2010). Effects of air temperature and relative humidity on coronavirus survival on surfaces. Applied \& Environmental Microbiology, 76(9), 2712-2717.

Chen, B., Liang, H., Yuan, X., Hu, Y., Xu, M., Zhao, Y., Zhu, X. (2020). Roles of meteorological conditions in COVID-19 transmission on a worldwide scale. MedRxiv.

Dalziel, B. D., Kissler, S., Gog, J. R., Viboud, C., Bjørnstad, O. N., Metcalf, C. J. E., \& Grenfell, B. T. (2018). Urbanization and humidity shape the intensity of influenza epidemics in US cities. Science, 362(6410), 75-79.

Epstein, P. R. (2001). West Nile virus and the climate. Journal of Urban Health, 78(2), 367-371.

Ficetola, G. F., \& Rubolini, D. (2020). Climate affects global patterns of COVID-19 early outbreak dynamics. MedRxiv.

Gupta, A., Bhatt, C. M., Roy, A., \& Chauhan, P. (2020). COVID-19 lockdown a win-dow of opportunity to understand the role of human activity on forest fire in-cidences in the Western Himalaya, India. Current Science. Https://Doi. Org/10.18520/Cs, 119, 390-398.

Huang, C., Wang, Y., Li, X., Ren, L., Zhao, J., Hu, Y., \& Gu, X. (2020). Clinical features of patients infected with 2019 novel coronavirus in Wuhan, China. The Lancet, 395(10223), 497-506.

Iqbal, N., Fareed, Z., Shahzad, F., He, X., Shahzad, U., \& Lina, M. (2020). Nexus between COVID19, temperature and exchange rate in Wuhan City: New findings from Partial and Multiple Wavelet Coherence. Science of Total Environment, 138916.

Jamil, T., Alam, I., Gojobori, T., \& Duarte, C. M. (2020). No evidence for temperaturedependence of the COVID-19 epidemic. Frontiers in Public Health, 8, 436.

Sajadi, M. M., Habibzadeh, P., Vintzileos, A., Miralles-wilhelm, F., \& Amoroso, A. (1992). This preprint research paper has not been peer reviewed. Electronic copy available at: https://ssrn.com/abstract $=3550308$. (410), 6-7.

Shi, P., Dong, Y., Yan, H., Zhao, C., Li, X., Liu, W., Xi, S. (2020). Science of the Total Environment Impact of temperature on the dynamics of the COVID-19 outbreak in China. Science of the 
Total Environment, 728(77), 138890. https://doi.org/10.1016/j.scitotenv. 2020.138890

Tamerius, J. D., Shaman, J., Alonso, W. J., Bloom-Feshbach, K., Uejio, C. K., Comrie, A., \& Gu, X. (2020). Urbanization and humidity shape the intensity of influenza epidemics in US cities. The Lancet, 76(8183), 1.

Tamerius, J. D., Shaman, J., Alonso, W. J., Bloom-Feshbach, K., Uejio, C. K., Comrie, A., \& Viboud, C. (2013). Environmental predictors of seasonal influenza epidemics across temperate and tropical climates. PLoS Pathogens, 9(3).

Tosepu, R., Gunawan, J., Effendy, D. S., Lestari, H., Bahar, H., \& Asfian, P. (2020). Correlation between weather and Covid-19 pandemic in Jakarta, Indonesia. Science of The Total Environment, 725, 138436.

Vandini, S., Corvaglia, L., Alessandroni, R., Aquilano, G., Marsico, C., Spinelli, M., \& Faldella, G. (2013). Respiratory syncytial virus infection in infants and correlation with meteorological factors and air pollutants. Italian Journal of Pediatrics, 39(1), 1.

Yuan, J., Yun, H., Lan, W., Wang, W., Sullivan, S. G., Jia, S., \& Bittles, A. H. (2006). A climatologic investigation of the SARS-CoV outbreak in Beijing, China. American Journal of Infection Control, 34(4), 234-236. 